\title{
Combining Ability and Standard Heterosis of Highland Maize (Zea Mays L.) Inbred Lines for Yield and Yield Related Traits
}

\section{Tefera Kumsa ${ }^{1 *}$, Habtamu Zeleke ${ }^{2}$ and Demissew Abakemal ${ }^{1}$}

${ }^{1}$ Ambo Agricultural Research center, EIAR, Ethiopia

${ }^{2}$ Haramaya University, Ethiopia

Article History

Received: 06.11.2020

Accepted: 17.11 .2020

Published: 24.12.2020

Journal homepage:

https://www.easpublisher.com

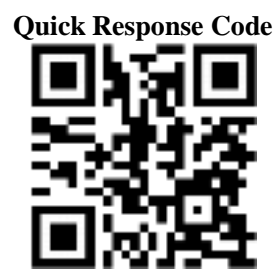

Abstract: Combining ability of inbred lines is important information in maize(Zea mays.L) hybrid breeding programs to incorporate genotypes from various germplasm sources. This study was conducted with germplasm developed using double haploid technology (DH) lines. Sixty-six $F_{1}$ crosses resulted from diallel crosses of 12 maize inbred lines with four standard checksArgane (AMH800), Kolba (AMH853), Jibat (AMH851) and Wenchi (AMH850) were evaluated based on partial diallel meeting fashion and its relative analysis to estimate general combining ability (GCA) and specific combining ability (SCA) for yield and yield related traits using alpha-lattice design with three replications during the 2017 cropping season at Ambo, Holeta and Kulumsa Agricultural research center of Ethiopian Institution of agricultural Reseach Institution. Analysis of variance showed that mean squares due to entries were significant for most of the traits studied, such as grain yield, thousand kennels weight, days to silking, ear per plant, plant height, ear height, husk cover, ear rot, ear aspect, plant aspect, kernel rows per row, ear length and ear diameter .Genotypes $\mathrm{x}$ environment interactions showed highly significant difference at $(\mathrm{p}<0.01)$ for most traits but significant $(\mathrm{p}<0.05)$ for grain yield.Mean squares due to crosses were significant $(\mathrm{p}<0.05)$ at two locations (Holeta and Kulumsa). Alleles at a locus can have an effect on the trait by themselves but can also affect the phenotype through interactions with other alleles the so called non- additive effect, while when allele of a single gene (in heterozagote )combine so that their combined effects equal the sum of their individual effects called additive gene action. GCA and SCA mean squares revealed significant $(\mathrm{p}<0.05)$ differences for grain yield and most yield related traits in all location and across location. Inbred lines P2, P9 and P12 were good general combiners as these lines showed significant and positive GCA effects for grain yield.Among the crosses, L1xL11, L2 x L12, L4xL9 and L5xL9 manifested positive and significant SCA effects for grain yield, indicating high yielding potential of the cross combinations across location.Therefore I suggest the maize breedrs for further utilization of the crosses in developing improved maize hybrid variety for highland adapted region.

Keywords: Cross combination, Double haploid lines, GCA, Standard Heterosis, SCA

Copyright (C) 2020 The Author(s): This is an open-access article distributed under the terms of the Creative Commons Attribution 4.0 International License (CC BY-NC 4.0) which permits unrestricted use, distribution, and reproduction in any medium for non-commercial use provided the original author and source are credited.

\section{INTRODUCTION}

Maize (Zea mays L.) is one of the world's leading crops and is widely cultivated as cereal grain that was domesticated in Central America. It is one of the most versatile emerging crops having wider adaptability. Globally, maize is known as queen of cereals because of its highest genetic yield potential (ICAR, 2012). Modern corn or maize was likely domesticated from teosinte in Mexico some 7,000 to 10,000 years ago and quickly spread through the Americas and it has become one of the most important crops at a local and global level [50].

Maize is a major staple food crop grown in diverse agro-ecological zones and farming systems, and consumed by people with varying food preferences and socio-economic backgrounds in Sub Saharan Africa (SSA) (FAOSTAT, 2015)[27]. Average maize yields among the developing countries, as an aggregate, are about one-third of those of the major maize producers. The world average maize grain yield is $5.64 \mathrm{t} \mathrm{ha}^{-1}$ (FAOSTAT, 2016)[26] whereas the national average yield of Ethiopia is $3.67 \mathrm{t} \mathrm{ha}^{-1}$ (CSA, 2016/17).

Among some of the largest maize producing countries, yield in China is around 5 tonnes/ha while in the Republic of South Africa it stands at around 3 tonnes/ha. This compare to 9 tonnes/ha in the United States, the highest world producer [26]. Maize plays a critical role in smallholder food security in Ethiopia. Its production is rapidly increasing to the highlands of Ethiopia where it has been a minor crop in the past [19]. It is estimated that the high altitude covers $20 \%$ of land 
devoted annually to maize cultivation, and more than $30 \%$ of small-scaled farmers in the area depend on maize production for their livelihood [53].

Combining ability analysis is of special importance in cross-pollinated crops like maize as it helps in identifying potential inbred parents that can be used for producing hybrids and synthetics [54]. The GCA and SCA variances were highly significant for most of the characters studied indicating importance of additive as well as non-additive types of gene action in controlling the traits related to grain yield [15]. SCA is due to genes showing non-additive effects and important for improved variety development in maize breeding scheme [51]. The study was conducted to evaluate highland adapted maize inbred lines using diallel mating design to estimate combining abilities and standard heterosis for grain yield and yield related traits which is avital important in developemnet of improved variety for the region.

\section{Materials ANd Methods Study Area}

The study was conducted at Ambo, Holeta and Kulumsa Agricultural Research Centre of Ethiopian Instituation of Agricultural Research in the main cropping season from 31 May 2017 to 12/29/2017.

\section{Experimental materials}

The experiment consisted of 66 diallel F1crosses formed using twelve inbred lines taken from Ambo highland maize breeding program four (4) commercial hybrid checks: check-1 (Argene), check-2 (Kolba), and check-3(Jibat) and check-4(Wenchi) which made up to a total of 70 entries in the hybrid trail.From the twelve inbred lines used for the experiment nine of them were $\mathrm{DH}$ lines that were introduced from CIMMYT Zimbabwe and the parental inbred lines were selected based on previous field performances in testcross evalutions by Ambo highland maize breeding program of Ethiopian Institution of Agricultural Reseaerch (Table1).

\section{Experimental Design and agronomic practice}

An Alpha lattice design (7x10) was used with three replications at each location. The Spacing was 75 $\mathrm{cm}$ between rows and $25 \mathrm{~cm}$ between plants. A single row plot of $5.25 \mathrm{~m}$ long was used. Each entry hads an equal chance of being randomly placed to any plot per block within a replication. Planting was done in the rainy season of 2017 after reliable moisture level of soil attained to ensure good germination and seedling development using two seeds per hill and thinned out to one plant after 35 days of planting. $200 \mathrm{~kg}$ of Urea and $150 \mathrm{~kg}$ of DAP was used as commercial fertilizer.

\section{Statistical Analysis}

Diallel analysis of variance was conducted to estimate general combining ability (GCA) and specific combining ability (SCA) of method IV and model I (fixed) considering the following statistical model Griffing $^{\text {ee }}$ [33].The most appropriate for obtaining unbiased estimates of combining abilities and gene action. Linear model used was as follows.

$Y i j k=\mu+g_{i}+g_{j}+s_{i j}+r k+e_{i j k}$,

Where Yijk is the individual plant observation on cross $i$ $\mathrm{x} \mathrm{j}$ in the kth replication. $\mu$ is the overall mean,

gi and gj are the parental effects or general combining ability (GCA) effects of the $i^{\text {th }}$ and the $j^{\text {th }}$ parents;

Sij is the specific combining ability of ith and jth parents, which is the non-additives of the parental effects; rk is replication effect, and eijk is the error associated with the $\mathrm{ijk}^{\text {th }}$ plant.

Table-1: List of inbred lines used in the formation of diallel crosses

\begin{tabular}{|l|l|l|}
\hline CODE & PEDIGREE & SOURCE \\
\hline P1 & (ZEWAc1F2-134-4-1-B-1-B*4/CML545)DH-31-B-\# & CIMMYT /HMBP \\
\hline P2 & (ZEWAc1F2-134-4-1-B-1-B*4/CML545)DH-33-B-\# & CIMMYT /HMBP \\
\hline P3 & (ZEWAc1F2-134-4-1-B-1-B*4/CML545)DH-34-B-\# & CIMMYT /HMBP \\
\hline P4 & (ZEWAc1F2-134-4-1-B-1-B*4/CML545)DH-44-B-\# & CIMMYT/HMBP \\
\hline P5 & (CML545-B-\# & AMBO-HMBP* \\
\hline P6 & $\begin{array}{l}\text { ZEWAc2F2-183-2-BBB-B/[INTA-2-1-3/INTA-60-1-2]-X- } \\
\text { CIMMYT /HMBP }\end{array}$ & \\
\hline P7 & (ZEWAc2F2-183-2-BBB-B/CML539)DH-3-B-\# & CIMMYT/HMBP \\
\hline P8. & (CML545/CML505)DH-35-B-\# & CIMMYT /HMBP \\
\hline P9. & (ZEWAc2F2-183-2-BBB-B/CML539)DH-7-B-\# & CIMMYT/HMBP \\
\hline P10. & (ZEWAc2F2-183-2-BBB-B/CML539)DH-13-B-\# & CIMMYT /HMBP \\
\hline P11. & (CML505/[INTA-2-1-3/INTA-60-1-2]-X-11-6-3-B) DH- & CIMMYT /HMBP \\
\hline P12. & FS620-B-B-\# & \\
\hline
\end{tabular}

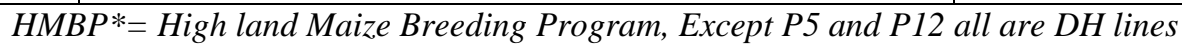




\section{RESULTS AND DISCUSSION}

\section{Analysis of Variance (ANOVA)}

Analysis of variance for mean square due to entries (genotypes) revealed highly $(\mathrm{p}<0.01)$ significant $(\mathrm{P}<0.05)$ difference for various traits indicating that there is a variability between materials evaluated which could be utilized for development of hybrid and synthetic varieties for studied traits. This is in line with Bullo and Dagne, 2016, Mohammad et al., 2016 who evaluate maize $F_{1}$ crosses for the same purpose. Mean square due to entries for anthesis silking interval and root lodge were highly significant $(\mathrm{p} \leq 0.01)$ at Holeta, indicating differences in the performance of the hybrid and commercial check varieties, but non-significant at Ambo and Kulumsa.

Mean square due to entries for ear aspect were highly significant at Ambo and Holeta but significant $(\mathrm{p} \leq 0.05)$ at Kulumsa. Mean square due to entries for $p$. turcicum (rust), were non- significant at all location.
Mean square due to entries for kernel rows per ear and number of kernels per row were highly significant $(\mathrm{p} \leq$ 0.01 ) at Holeta and Kulumsa but non-significant at Ambo. Mean square due to entries for days to maturity, stalk lodge and E. turcicum leaf blight (TLB) revealed non - significant in all locations. At Ambo statistical difference was found in 10 variables $(\mathrm{p} \leq 0.01)$ and three variables $(p \leq 0.05)$ while at Holeta statistically high significant difference were found in thirteen variables. At Kulumsa site statistical difference at $\mathrm{p} \leq$ 0.01 levels were found among fifteen and one variables, respectively.

The experiment result showed that analysis of variance at individual environment revealed that mean of sum squares due to genotypes was significant for most characters in all environments similar with the result of different authors $[41,18,11]$ that indicate the chance for computing further genetic analysis.

Table-2: Mean squares due to genotypes and error for grain yield and related traits at three locations in 2017

\begin{tabular}{|c|c|c|c|c|c|c|}
\hline \multicolumn{7}{|c|}{ Means Squares } \\
\hline \multicolumn{2}{|c|}{ Ambo } & \multicolumn{2}{|c|}{ Holeta } & \multicolumn{3}{|c|}{ Kulumsa } \\
\hline Genotypes & Error & Genotypes & Error & Genotype & Error & \\
\hline Traits & $\mathrm{df}=69$ & $\mathrm{df}=111$ & $\mathrm{df}=69$ & $\mathrm{df}=111$ & $\mathrm{df}=69$ & $\mathrm{df}=111$ \\
\hline GY & $9.87 * *$ & 2.44 & $9.84 * *$ & 1.32 & $9.79 * *$ & 2.17 \\
\hline $\mathrm{AD}$ & $31.82 *$ & 6.61 & 66.4 & 64.6 & $30.58 * *$ & 6.23 \\
\hline SD & $39.48 *$ & 9.71 & 2.9 & 70.11 & $25.33 * *$ & 3.17 \\
\hline ASI & 0.024 & 0.01 & 42.39 & 63.59 & 0.01 & 0.01 \\
\hline $\mathrm{PH}$ & $1023 * *$ & 334.56 & $1250 * *$ & 211.4 & $422.16^{* *}$ & 167.66 \\
\hline $\mathrm{EH}$ & $496.2 * *$ & 117.79 & $599.1 * *$ & 56.77 & $278.14 * *$ & 63.48 \\
\hline $\mathrm{RL}$ & 0.61 & 0.53 & 121.2 & 182.1 & NL & NL \\
\hline SL & 3.34 & 2.94 & 0.08 & 0.08 & NL & NL \\
\hline PS & 0.01 & 0.01 & 0.01 & 0.03 & 0.07 & 0.06 \\
\hline ET & 0.01 & 0.01 & 0.09 & 0.08 & $0.01 *$ & 0.01 \\
\hline $\mathrm{MD}$ & 4.9 & 3.96 & 1768 & 1706 & 1048.58 & 927.2 \\
\hline EPP & $0.22 * *$ & 0.01 & $0.18 * *$ & 0.07 & $0.15 * *$ & 0.07 \\
\hline $\mathrm{HC}$ & $71.53 * *$ & 8.56 & $110.23^{* *}$ & 15.79 & $1.65 * *$ & 0.41 \\
\hline ER & $5.86 * *$ & 2.95 & $16.48 * *$ & 4.69 & $13.65 * *$ & 4.69 \\
\hline EA & $0.44 * *$ & 0.08 & $1.41 * *$ & 0.19 & $0.38 * *$ & 0.1 \\
\hline PA & $0.19 * *$ & 0.08 & $0.81 * *$ & 0.24 & $0.51 * *$ & 0.13 \\
\hline RPE & 0.79 & 0.86 & $2.4 * *$ & 1.17 & $2.21 * *$ & 0.65 \\
\hline KPR & 17.99 & 15.67 & $10.66 * *$ & 5.15 & $21.17 * *$ & 8.98 \\
\hline EL & $8.46 * *$ & 0.82 & $12.43 * *$ & 1.68 & $6.44 * *$ & 1.02 \\
\hline ED & $0.15 * *$ & 0.03 & $0.18 * *$ & 0.08 & $0.45 * *$ & 0.1 \\
\hline TKW & $7675.23 *$ & 700.15 & $4737.14 * *$ & 940.84 & $5685.04 * *$ & 1212.15 \\
\hline
\end{tabular}

$* *=$ Significant at $(p<0.01), *=$ significant at $(p<0.05), G Y=$ grain yield, $A D=$ number of days to anthesis, $S D=$ number of days to silking, $A S I=$ anthesis - silking interval, $P H=$ plant height, $E H=$ ear height, $R L=$ root lodge, $S L=$ stalk lodge, EPP $=$ number of ears per plant, $H C=$ husk cover, $E R=e$ ar rot, $P S=P$. turcicum, $E T=E$. turcicum leaf blight, $E P P=$ ear per plant, DM=days to maturity, $E A=$ ear aspect, $P A=$ plant aspect, $R P E=$ number of row per ear, $K P R=$ number of kernel per row, EL=ear length, ED=ear diameter, $T K W=$ thousand kernel weight, $N L=$ no lodge.

The combined analysis of variance was made for grain yield, days to anthesis and to silking, plant and ear height, ear per plant, husk cover, ear rot, plant and ear aspect, kernel rows per ear, ear length, ear diameters and thousand kernel weight. Across location analysis of variance revealed highly significant $(\mathrm{p} \leq 0.01)$ differences among genotype for all traits computed [31]. As genotypes differed significantly, the presence of considerable genetic variability among traits were expected (Table 3 ). The analysis of variance revealed 
that mean squares due to entries were highly significant $(\mathrm{p} \leq 0.01)$ in all location for traits such as grain yield, days to anthesis, days to silking, plant and ear height, ear per plant, bad husk cover, ear rot, plant aspect, ear length, ear diameter and thousand kernel weight (Table 3).

Table-3: Across locations mean squares due to genotypes, genotype $\mathrm{x}$ location and error for grain yield and related traits in 2017

\begin{tabular}{|c|c|c|c|c|c|}
\hline \multicolumn{6}{|c|}{ Pooled mean square } \\
\hline Traits & Loc. & Genotypes & $\mathrm{GxE}$ & Error & $\mathrm{CV}$ \\
\hline$(\mathrm{df}=2)$ & $(\mathrm{df}=69)$ & $(\mathrm{df}=138)$ & $(\mathrm{df}=333)$ & & \\
\hline GY & $4036.66 * *$ & $23.7 * *$ & $2.58 *$ & 2.01 & 19.4 \\
\hline TKW & $976877.1^{* *}$ & $13356.2 * *$ & $1847.5^{*}$ & 951.05 & 10.6 \\
\hline SD & $12018.2 * *$ & $92.5 * *$ & $9.8^{* *}$ & 6.47 & 2.7 \\
\hline EPP & $7.1 * *$ & $2.8 * *$ & $0.11 * *$ & 0.075 & 19 \\
\hline $\mathrm{PH}$ & $61192.3 * *$ & $1965.2 * *$ & $302.3^{*}$ & 237.79 & 8.7 \\
\hline EH & $24827.6 * *$ & $1116.47 * *$ & $120.8^{* *}$ & 79.35 & 10.9 \\
\hline $\mathrm{HC}$ & $3158.5 * *$ & $113.55 * *$ & $113.6 * *$ & 8.25 & 36.5 \\
\hline ER & $374.9 * *$ & $20.35 * *$ & $7.77 * *$ & 4.58 & 5.3 \\
\hline EA & $18.48 * *$ & $1.3 * *$ & $0.39 * *$ & 0.123 & 10.8 \\
\hline PA & $43.86^{* *} *$ & $0.98 * *$ & $0.25 * *$ & 0.15 & 13.9 \\
\hline RPE & $10.4 * *$ & $2.8 * *$ & $0.9 * *$ & 0.69 & 6.5 \\
\hline EL & $42.01 * *$ & $22.64 * *$ & $1.95 * *$ & 1.24 & 7.9 \\
\hline ED & $20.45 * *$ & $0.45 * *$ & $0.21 * *$ & 0.09 & 6.0 \\
\hline
\end{tabular}

$\mathrm{df}$ of genotypes $=69, \mathrm{df}$ of error $=333, * *$ Significant at 0.01 level of probability; $*$ significant GxE $=$ genotype $*$ environment, at $\mathrm{p}<0.05 \%$ level of probability.

The Pooled analysis of variance revealed that the mean squares due to location, genotypes, genotypes by environment manifested highly significant difference $(\mathrm{p}<0.01)$ for all traits but significant for grain yield $(\mathrm{p}<0.05)$ probably the significances difference is maybe the existence of small genetic difference between genotypes and environmental effects.

In support of the present finding, significant differences among genotypes for grain yield $\mathrm{th}^{-1}$ and yield related traits in different sets of maize genotypes was reported by earlier studies [30].The existence of highly significant differences for all traits across location indicates the presence of inherent (genetic) variation among the materials evaluated, which makes selection possible for further breeding program [17]. Across location managed optimum environment, significant differences was detected among genotypes for grain yield.

\section{b) Mean Performance of genotypes}

Pooled analysis of variance was made for fifteen traits which show significant difference at two or more locations i.e. that traits showed homogeneity of variances only. This indicate that considerable genetic variability for various traits existed among the material under studies. Pooled mean square of genotypes, genotype $\mathrm{x}$ location and error are presented (Table 4).

Among genotypes evaluated across location the maximum, grain yield 10.9 and $10.6 \mathrm{t} \mathrm{h}^{-1}$ was recorded from in L5xL12 and $\mathrm{L} 3 \times \mathrm{LL} 12$, respectively, whereas the minimum $4.4 \mathrm{t} \mathrm{h}^{-1}$ was found from L1xL3, L1xL4 and L5xL8 crosses. The average mean grain yield across location was $7.7 \mathrm{t} \mathrm{h}^{-1}$. In this study the highest mean performance of the genotypes might have been due to good combiner of the parents having highest GCA effects. In agreement with this studies experimental varieties evaluated by different researchers $[16,6]$; indicatd genotypes evaluated perform that better than the best check variety for most of yield and other traits of crosses.Therefore, the variability existed in the tested crosses could help in the improvement of these traits.

Maximum number of days to tasseling (103.6 days) was found from the cross L4xL5 and the minimum number of days to tasseling was 88.4 days for hybrids as in L6xL10. Number of days to silking varied from 90.1 to 105.9 for hybrids as in L6xL10 and L4xL5 respectively. Maximum plant height was $212.7 \mathrm{~cm}$ for hybrids as in L5xL12, among hybrids minimum plant height $(156.6 \mathrm{~cm})$ was found from L5xL8. Here the hybrid checks Kolba and Argane gave the higher plant height than all. Ear height of hybrids varied from $64.3 \mathrm{~cm}$ to $107.0 \mathrm{~cm}$ in L6xL11 and L2xL12 respectively (Appendix 4).

The number of ears per plant was in between 1.2 to 2.0 for hybrids, for crosses L4xL8 and L5xL12 respectively. Higher ear rot severity was found from the cross L6xL7 and the minimum was found from cross combination L2xL12. Ear length record was in the range of 10.6 to $17.7 \mathrm{~cm}$ for the crosses $\mathrm{L} 1 \mathrm{xL} 4$ and L5xL12 respectively. Maximum ear diameter $(4.7 \mathrm{~cm})$ was found from the cross L5xL12 and other 3 crosses including hybrids check Kolba and the least $(3.8 \mathrm{~cm})$ 
was obtained from L1xL4 other 3 crosses in the experiment.

\section{c) Estimation of Standard Heterosis}

The mean sum of squares due togenotypes were highly significant for all the traits, indicate that the material selected for the present investigation was quite appropriate for further genetic analysis due to the variability found among genotypes. The magnitude of heterosis at individual and across location (pooled) exhibited by different crosses over Kolba, Jibat, Wenchi and Argane checks for all the traits is presented in(Table4).The standard heterosis of tested genotypes ranged from $-29.2 \%$ to $72.72 \%$. The positive standard heterosis was shown by most of hybrids for grain yield in all location and across location.

Superior hybrids, which manifested $>15 \%$ standard heterosis over check hybrids were highest standard heterosis, however in Ethiopian context $>10 \%$ experimental hybrids yield advantage over the standard check was acceptable. Grain yield improvement is one of the most important objectives in maize breeding program according to [49]. Tthe presence of directional dominance effects at the loci which affecting the trait and difference in gene frequencies between the lines, being crossed indicated the existence of heterosis [21].

For pooled analysis across location genotypes attained lowest standard heterosis over the hybrid check Kolba so that selection of high specific combining ability crosses was unacceptable for variety development. Hybrids L5xL9 (2.8\%) showed higher standard heterosis over the hybrids check Jibat. Hybrids L5xL9 (18.55\%) and L5xL11 (10.83\%) showed higher standard heterosis over the hybrid check Wenchi. However, hybrid such as L5xL9 (11.00\%) recorded highest standard heterosis over the hybrids check Argane across location (table 5).

Table-5: Estimation of Standard Heterosis

\begin{tabular}{|l|l|l|l|l|l|l|l|l|l|}
\hline \multicolumn{7}{|c|}{ Grain yield (GY) in ton versus \% Standard Heterosis (SH) in 2017} \\
\hline \multicolumn{7}{|c|}{ SH versus checks (\%) across location Crosses SH versus checks (\%) Ambo } \\
\hline Crosses & Kolba & Jibat & Wenchi & Argane & Kolba & Jibat & Wenchi & Argane & \\
\hline L2xL11 & -21.1 & -15.71 & -2.80 & -8.95 & L1xL12 & -9.91 & 3.91 & 13.85 & 16.81 \\
\hline L2xL12 & -11.5 & -5.50 & 8.98 & 2.05 & L2xL4 & -5.56 & 8.93 & 19.34 & 22.43 \\
\hline L3xL10 & -19.3 & -13.80 & -0.57 & -6.90 & L2xL9 & -17.39 & -4.7 & 4.39 & 7.10 \\
\hline L3xL11 & -19.5 & -13.98 & -0.81 & -7.12 & L3xL5 & -19.91 & -7.6 & 1.21 & 3.83 \\
\hline L4xL10 & -19.3 & -13.80 & -0.57 & -6.90 & L4xL8 & -9.91 & 3.91 & 13.85 & 16.81 \\
\hline L5xL6 & -19.2 & -14.00 & -0.46 & -6.80 & L5xL9 & -17.30 & -4.6 & 4.65 & 7.10 \\
\hline L5xL9 & -3.74 & 2.81 & 18.55 & 11.00 & L7xL12 & -19.13 & -6.7 & 2.22 & 4.85 \\
\hline L5xL11 & -10.0 & -3.91 & 10.83 & 3.77 & L9xL11 & -15.65 & -2.7 & 6.59 & 9.41 \\
\hline L9xL12 & -10.9 & -12.28 & 1.15 & -5.31 & L9xL12 & -2.41 & 12.6 & 23.41 & 26.61 \\
\hline L11xL12 & -17.6 & -11.98 & 1.51 & -4.96 & L10xL12 & -20.00 & -7.6 & 1.11 & 3.72 \\
\hline
\end{tabular}

$\mathrm{Gy}=$ grain yield, $\mathrm{SH}=$ standard heterosis, - ve value $=$ higher check, +ve value $=$ higher hybrids

Table-5: Con'd

\begin{tabular}{|c|c|c|c|c|c|c|c|c|c|}
\hline \multicolumn{10}{|c|}{ Grain yield (GY) in ton versus \% Standard Heterosis (SH) in 2017} \\
\hline \multicolumn{5}{|c|}{ SH versus checks $(\%)$ Holeta } & \multirow[t]{2}{*}{ Crosses } & \multicolumn{4}{|c|}{ SH versus checks $(\%)$ Kulumsa } \\
\hline Crosses & Kolba & Jibat & Wenchi & Argane & & Kolba & Jibat & Wenchi & Argane \\
\hline L2xL9 & -21.24 & -17.82 & 5.95 & 25.35 & L2xL5 & 8.31 & 20.10 & 40.24 & 72.12 \\
\hline L3xL12 & -16.99 & -13.40 & 11.42 & 32.11 & L2xL9 & 1.04 & 12.1 & 30.86 & 60.6 \\
\hline L5xL7 & -23.41 & -19.85 & 3.09 & 21.97 & L3xL6 & -4.67 & 5.71 & 23.45 & 51.51 \\
\hline L5xL9 & -26.54 & -23.36 & -1.19 & 16.9 & L3xL7 & 8.67 & 20.51 & 40.7 & 72.72 \\
\hline L5xL11 & -27.43 & -24.28 & -2.40 & 15.49 & L3xL11 & -7.53 & 2.54 & 19.75 & 46.97 \\
\hline L5xL12 & -10.62 & -6.7 & 20.23 & 42.25 & L4xL8 & -4.38 & 6.02 & 23.82 & 51.9 \\
\hline L7xL12 & -23.89 & -20.59 & 2.38 & 21.12 & L4xL10 & 0.11 & 10.99 & 29.62 & 59.10 \\
\hline L8xL12 & -22.12 & -18.74 & 4.76 & 22.73 & L5xL12 & -5.62 & 4.65 & 22.22 & 50.00 \\
\hline L9xL12 & -29.2 & -26.13 & -4.76 & 12.67 & L6xL12 & -9.43 & 0.43 & 17.31 & 43.94 \\
\hline L11xL12 & -23.00 & -19.67 & 3.57 & 22.53 & L7xL11 & -8.48 & 1.47 & 18.51 & 45.51 \\
\hline
\end{tabular}

$\mathrm{Gy}=$ grain yield, $\mathrm{SH}=$ standard heterosis, - ve value $=$ higher check, +ve value= higher hybrids.

\section{d) Analysis of combining ability}

For combining ability analysis of variance revealed that the variances due to GCA and SCA were highly significant $(\mathrm{p}<0.01)$ for some traits such as grain yield, days to anthesis, to silking ,husk cover, ear rot, row per row, kernel per row ,ear length, ear diameter and 1000-kernel in all location, therefore there was enough variation at individual and across location for a successful in selection of the desirable cross combinations [36-38] the importance of both GCA and SCA effects in determining the inheritance of most characters studied in line with the result ofsome 
authors like $[15,43,17]$. And also this result indicated existence of genetic variability in the parental lines and involvement of both additive and non-additive gene effects in the inheritance of these traits and although the contribution of each component may vary according to character.

\section{e) Analysis of combining ability for across locations}

Combined genetic analysis was made for trait that showed significant difference such as grain yield, kernel per ear, ear length, ear diameter, husk cover and ear rot. Mean square due to crosses were highly significant $(\mathrm{p}<0.01)$ to all traits analyzed over location except grain yield and row per ear that showed nonsignificant difference. The combined analysis of variance( GCA and SCA ) on genetic components due to mean square, were highly significant $(\mathrm{p}<0.01)$ for kernels per ear, ear length, ear diameter and husk cover, whereas grain yield were significant due to GCA only (Table 9).

Mean square due to SCA for ear diameter and ear rot showed highly significant difference $(p<0.01)$ among crosses evaluated across locations. Mean square due to crosses manifested highly significant $(\mathrm{p}<0.01)$ for, husk cover, ear rot, kernel per row, ear length and ear diameter but non-significant for grain yield.

Highly significant variance due to environment was observed for most characters indicating that the traits such as grain yield, ear diameter and ear rot were influenced by environmental factors. In the current study, mean squares due to environment were nonsignificant for kernel per row, except grain yield, ear length and husk cover which is in line with the result of Gudeta, 2007[35]. Mean square due to crosses revealed that highly significant $(\mathrm{p}<0.01)$ variation were observed across location for all character tested which is in agreement with the report of Legesseet al., 2009 [38] and Reddy et al., 2016 [48]. In similar manner mean square due to cross by environment revealed highly significant difference for husk cover and ear rot while traits like kernel per row, ear length and ear diameter and kernels per row displayed significant difference but grain yield not manifested significant difference due to cross by environment which is in line with the report of Chukwu et al., 2016[16] and Kulka et al., 2018. Mean square due to GCA x environment revealed significant difference only for grain yield, ear diameter and ear rot than SCA $x$ environment interaction which is in agreement with other authors [14, 39].

All characters evaluated for mean square due to SCA $\mathrm{x}$ environment revealed non-significant difference and stability of SCA effects across environments was indicated as similarly observed by Machado et al. [40] and Lilian et al., [39]. For most studied traits the magnitude of the interaction was lower for GCAxenvironment than SCAx environments, i,e non-additive genetic variance was influenced by environments and also the non-additive effect component interacted more with the environments than the additive effect similar with the findings of Dagne et al., [16], and Mohammed, 2015 [42].

Table-9: Mean square of combined analyses of genetic variance for grain yield and agronomic characterstics of

\begin{tabular}{|c|c|c|c|c|c|c|c|}
\hline \multicolumn{8}{|c|}{ maize } \\
\hline Source & df & Yield & KPE & EL & ED & HC & ER \\
\hline ENV & 2 & $134.02 * *$ & 0.09 & 4.66 & $2.54 * *$ & 14.06 & $57.26 * *$ \\
\hline REP (ENV) & 6 & 5.64 & $13.88^{*}$ & 3.68 & $0.57 * *$ & 17.96 & $64.02 *$ \\
\hline Crosses & 65 & 5.52 & $32.64 * *$ & $16.22 * *$ & $0.2 * *$ & $204.91 * *$ & $197.12 * *$ \\
\hline Crosses*Env & 130 & 5.63 & $9.95^{*}$ & $6.22 *$ & $0.12 *$ & $73.55^{* *}$ & $69.53 * *$ \\
\hline $\mathrm{GCA}$ & 11 & $9.81 *$ & $22.38 * *$ & $10.31 * *$ & $0.27 * *$ & $157.96 * *$ & $114.73 * *$ \\
\hline SCA & 54 & 4.65 & $34.74 * *$ & $17.42 * *$ & $0.18^{* *}$ & $214.48 * *$ & $213.90 * *$ \\
\hline $\mathrm{GCA} * \mathrm{ENV}$ & 22 & $8.31 *$ & 1.72 & 2.67 & $0.17 * *$ & 9.07 & $20.30 *$ \\
\hline SCA * ENV & 108 & 5.42 & 1.36 & 2.07 & 0.09 & 4.41 & 7.61 \\
\hline Error & 528 & 5.26 & 6.29 & 4.2 & 0.1 & 33.32 & 33.74 \\
\hline Mean & & 7.34 & 31.25 & 14.66 & 4.49 & 9.48 & 9.11 \\
\hline $\mathrm{CV}$ & & 18.63 & 8.03 & & 7.20 & 45.88 & 43.69 \\
\hline
\end{tabular}

$\mathrm{Gy}=$ grain yield, $\mathrm{KPE}=$ Kernel per row, $\mathrm{EL}=$ ear length, $\mathrm{ED}=$ ear diameter, $\mathrm{HC}=$ husk cover $\mathrm{ER}=$ ear rot

\section{Effects general combining ability (GCA)}

Analyses of variances (ANOVA) of general combining ability effects were made for traits that revealed significant differences among genotypes (parents and hybrids). The deviation of its progeny mean from the mean of all the lines used for a particular genotype measured is considered as general combining ability .General combinig ability happened due to the genetic additive effects and to the epistatic effects that include only additive combinations [13].

\section{Across location general combining ability effects}

The combining ability analysis was performed to obtain information on selection of better parents and crosses for their further use in breeding program. The combined data of mean performance across three environments for grain yield and other agronomic traits of the twelve inbred lines and 66 F1 crosses showed significant difference for most traits such as grain yield, 1000-kernel weight, and number of kernel per row, ear length, ear diameter, husk cover and ear rot [41]. 
Combining ability analysis provides information regarding potential of parents and diallel analysis are conducted for estimation of various components i.e. GCA and SCA [34]. Of all twelve parents, L2 $(0.60 * *)$, L4 $(0.33 *)$ and L9 $(0.72 * *)$ manifested significant and highly significant positive GCA effects and L11 (-0.67**) possessed in negative direction for grain yield in line with the result of Ofori et al., 2015. The parental lines had positive GCA effects indicating the presence of favorable alleles that contributed to grain yield inceament. The results indicated that the existence of high additive gene action in F1 crosses. For grain yield further progress can be achieved in these genotypes through recurrent selection methods. This result is in line with the finding of Musila et al., [45]. The parental lines could be used in breeding program to improve maize yield with desirable traits as similarly reported by Dagne et al.,[16]; Demissew et al., [17], and Matin et al. Both GCA component $(0.72 * *)$ and SCA component $(2.84 * *)$ that showed highly significant indicating the importance of both additive and non-additive gene action in governing the inheritance of this trait similar result reported by Afshar and Bahram, 2012[5].

Further the evaluated parental lines ranked based on the respective combining abilities of the characters studied and the value of GCA estimation. While doing so L9 ranked first followed by L2 (Table 13). Therefore, the inbred lines can be used for improvement of the respective traits in any breeding program wherever hybridization is involved. The lines having good GCA can be utilized straightaway as parents for production of good hybrids by crossing with other different lines and can also be utilized in the development of synthetic varieties.

Among twelve parental lines evaluated for their combining abilities computing with different grain yield and related traits under study, L4 recorded significant GCA effects in desirable direction for five different parameters viz., grain yield, 1000-kernel weight, ear length, ear diameter, husk cover and ear rot . Also L9 provided significant GCA effects in desirable direction for two characters viz., grain yield and 1000kernel weight followed by L5 that scored significant GCA effects for three traits such as kernels per row, husk cover and ear rot reaction (Table13).

Regarding pooled analysis for thousand kernel weight, L4 $(16.52 *)$ and L9 $(35.64 * *)$ attained significant and highly significant and positive GCA effects, hence 1000-kernel weight directly contributes to increased grain yield. Those line that contribute positive GCA effects have potential for genetic improvement of grain yield. To the undesired direction L2 $\left(-31.81^{* *}\right)$ and L11 $(-32.8 * *)$ had negative and highly significant GCA effects for thousand kernel weight, suggesting this line could be taken as poor combiner for this traits. Positive and negative significant GCA effects were observed and reported by $[2,7,6,32]$.

In case of pooled data of number of kernels per row over environment inbred lines such as L5 $\left(0.89^{* *}\right)$ and L12 $(0.47 *)$ was manifested significant positive GCA effects, in the other hand L1 $(-0.89 * *)$, L3 ($\left.0.49^{*}\right)$ and L11 $\left(-0.55^{*}\right)$ showed significant negative GCA effects to the undesired direction. Those lines attained positive and significant GCA effects for grain yield related traits such as number of kernels per row were considered as good combiner and utilized for further improvement of traits in agreement with the report of Abdel-Moneam et al. Significant GCA mean square were implied the importance of additive gene action in controlling the inheritance of kernels per $\operatorname{row}[35,6]$.

The pooled data of inbreed lines that manifested positive significant GCA effects for ear length were L2 $\left(0.41^{*}\right)$ L4 $(0.40 *)$ and L6 $(0.53 * *)$ while to the undesired direction lines that showed negative and significant GCA effects were L3 (-0.46*) and L1 $1\left(-0.40^{*}\right)$. In the case of ear diameter estimate of GCA effects for inbred lines such as L2 $(0.07 *)$, L4 $\left(0.12^{* *}\right)$ and L6 $\left(0.08^{*}\right)$ displayed significant positive effects, whereas to the undesired direction significant GCA effects were recorded from L11 (-0.07*).

For both ear length and diameter lines displayed positive and significant GCA effects taken as good combiners for the improvement of the traits. In line with the current result (Amiruzzamam et al., [8],Tolera [32]; Tessema et al., [53] and AbdelMoneam et al. [1] reported both positive and negative GCA effects for ear length and diameter were recorded ,however the authors considered lines with significant positive GCA effects as good combiners for improving this trait. L2, L4 and L6 had positive GCA effects for grain yield, while all lines with significant negative GCA effects for ear length and ear diameter were poor combiner for grain yield, indicating the direct contribution of ear length and ear diameter to grain yield and also in agreement with the finding of Matin $e t$ al. Dufera.

Inbred lines that attributed highly and significant positive GCA effect for bad husk cover were L5 (1.81**), L7 $\left(1.75^{* *}\right)$ and L4 $(1.44 *)$ while lines displayed negative significant GCA effects were L2 ($1.29 *)$, L3 $(-1.23 *)$ and L12 $(-2.33 * *)$ for the same traits. For bad husk cove inbred lines showed significant and negative GCA effect considered as lines having desirable gene and good combiner that indicates having closed (firm) husk cover. Similar finding were reported by other authors Girma et al. [50], and Dufera, 2017. 
Table-13: Across location GCA estimates of different yield and yield related traits in 2017

\begin{tabular}{|l|l|l|l|l|l|l|l|}
\hline Parents & GY(ton) & TKW(gm) & KPR(no) & EL(cm) & ED(cm) & HC(no) & ER(no \\
\hline L1 & 0.24 & 11.17 & $-0.89^{* *}$ & 0.13 & 0.01 & -0.94 & -1.07 \\
\hline L2 & $0.60^{* *}$ & $-31.8^{* *}$ & 0.26 & $0.41^{*}$ & $0.07^{*}$ & $-1.29^{*}$ & -0.88 \\
\hline L3 & 0.02 & 0.56 & $-0.49^{*}$ & $-0.46^{*}$ & -0.05 & $-1.23^{*}$ & -1.07 \\
\hline L4 & $0.33^{*}$ & $16.52^{*}$ & 0.18 & $0.40^{*}$ & $0.12^{* *}$ & $1.44^{*}$ & $1.35^{*}$ \\
\hline L5 & -0.16 & -7.77 & $0.89^{* *}$ & -0.08 & -0.01 & $1.81^{*}$ & $1.27^{*}$ \\
\hline L6 & -0.21 & -10.38 & 0.33 & $-.53^{* *}$ & $0.08^{*}$ & $0.06^{*}$ & 0.65 \\
\hline L7 & 0.24 & 11.96 & 0.21 & -0.04 & 0.01 & $1.75^{*}$ & $1.4 * *$ \\
\hline L8 & 0.03 & 1.80 & 0.28 & 0.21 & 0.01 & -0.58 & -0.43 \\
\hline L9 & $0.73^{* *}$ & 35.64 & -0.43 & 0.31 & -0.02 & 0.96 & 0.65 \\
\hline L10 & -0.18 & -8.98 & -0.04 & -0.07 & -0.05 & 0.12 & 0.18 \\
\hline L11 & $-0.67^{* *}$ & $-32.8 * *$ & $-0.55^{*}$ & $-0.40^{*}$ & $-0.07^{*}$ & 0.24 & 0.01 \\
\hline L12 & 0.28 & 14.07 & $0.47^{*}$ & -0.13 & -0.02 & $-2.3 * *$ & $-2.1 * *$ \\
\hline SE(gi) & 0.17 & 3.43 & 0.15 & 0.19 & 0.05 & 0.36 & 0.54 \\
\hline SE(gi-gj) & 0.25 & 5.11 & 0.23 & 0.29 & 0.07 & 0.53 & 0.80 \\
\hline
\end{tabular}

$* *=$ highly significant difference $(\mathrm{P}<0.01), *=$ significant difference $(\mathrm{P}<0.05), \mathrm{GY}=$ grain yield, TKW $=1000-\mathrm{kernel}$ weight, $\mathrm{KPR}=$ kernels per row, $\mathrm{EL}=$ ear length, $\mathrm{ED}=$ ear diameter, $\mathrm{HC}=$ husk cover, $\mathrm{ER}=$ ear rot, $\mathrm{SE}=$ standard error at LSD 0.05 probability level.

At across location pooled data for ear rot reaction, L4 $\left(1.35^{*}\right)$ and L5 (1.27*) manifested significant and L7 (1.41**) highly significant and positive GCA effect. The inbred line L4 (1.35*) also showed significant positive GCA effect for grain yield and husk cove. This indicated the need for further effort to improve this inbred line and other inbred lines that was good combiners for grain yield but contain undesirable genes which make the line susceptible to all common disease and poor husk cover which inherited due to gene linkage and the law of gene drag generally, inbred lines with negative GCA estimation were considered as a good combiner for all disease parameters in agreement with the finding of other authors Berhanu, Legesse et al. and Lilian et al.

Whenever GCA interacted highly with environments there is a need to select specific parents for hybrid formation in specific niches. This shows that except for grain yield, non-additive gene action played a minor role in the inheritance of other traits: days to silking, ear height, husk cover and ear rot resistance. Hallauer and Miranda, Dagne Wegary et al., also found dominance effects to be more important for grain yield than for other traits.

\section{Effects of Specific Combining Ability (SCA)}

The specific combining ability effects at individual location and across location was computed and given as follows for traits that showed significant mean squares due to SCA in genetic analysis of diallel F1 crosses. Significant positive specific combining ability effects were found in almost in all studied traits in both individual and across location indicating presence of genetic diversity and presence of inbred lines belonging to different heterotic groups as revealed from their response to respective crosses.

\section{Across location SCA estimates of different yield and yield related traits}

Analysis of variance for specific combining ability for different characters of grain and related trait under study for across location were computed hence their SCA estimates were presented (Table 17). The screening and selection of lines in available germplasm that could produce better cross combinations of important characters is the utilization of hybrid vigor (heterosis).

The cross combination L1 x L3 $(11.05 * *)$, L2xL9 (6.71**), L4xL5 (16.29**), contributed positive and highly significant SCA effect for ear rot in the undesirable direction. Whereas crosses that showed highly significant negative SCA effects were L3xL11 ($3.29 *)$, L4xL6 (-7.56**), L5xL10 (-7.38**), L9xL10 ($\left.\left.4.36^{*}\right) 2.68 * *\right)$ in the desired direction for the same traits (Table 17). For rows per ear the cross combination of L3xL4 (1.71**), L5xL12 (1.23*), L6 x L7 (1.31*) and L8xL11 (1.28**), showed positive and highly significant SCA effect in the desirable direction. While to the undesirable direction crosses L3xL9 (-1.55**), L3xL12 $(-1.51 * *), \quad$ L3xL11 $(-98.9 * *), \quad$ L3xL12 ($\left.111.48^{* *}\right), \operatorname{L5xL11}\left(-1.08^{* *}\right)$, were recorded highly specific combining ability effects followed by L4xL6 ($\left.54.11^{*}\right)$ and L8xL9 $\left(-59.25^{*}\right)$ which manifested negative significant effects (Table 17).

To the desirable direction crosses such as L4 $\mathrm{x}$ L8 $\quad\left(5.86^{* *}\right), \quad$ L4xL12 $\left(3.85^{* *}\right), \quad$ L5xL11 $\left(3.42^{*}\right)$ manifested positive and highly significant SCA effect for number of kernels per row. In the other hand crosses L1xL4 $\left(-6.57^{* *}\right), \quad$ L2xL4 $(-2-.36 * *)$, was obtained highly significant and negative SCA effect the same traits in undesirable direction (Table 17).

The cross L4xL8 (2.86**), L4xL9(1.41*), $\operatorname{L5xL7}\left(2.11^{* *}\right), \quad \operatorname{L5xL8}(2.27 * *), \operatorname{L10xL12}(2.59 * *)$, expressed highly significant $(\mathrm{p}<0.01)$ and positive SCA 
effect for ear length, whereas the crosses L1xL4(2.36*), L3xL12(1.33*) and L7xL12(-3.24*), provided highly significant $(\mathrm{p}<0.01)$ and negative SCA effects for the same traits in undesired direction. Considering the character ear diameter cross combination of L1xL2 $(0.37 * *), \quad \operatorname{L1xL12}\left(0.52^{* *}\right)$ and $\operatorname{L6xL7}(0.4 * *)$, manifested highly significant SCA effects in the desirable direction whereas crosses of L1xL7 (-0.35**), L4xL12 $\left(-0.33^{*}\right), \operatorname{L5xL11}\left(-0.42^{* *}\right)$ and L9xL12 ($0.32 *)$ showed highly significant and negative SCA effects to the negative direction and L5xL11 $\left(-0.27^{*}\right)$ and L9xL11 $\left(-0.15^{*}\right)$ as well (Table17). While assessing the performance of parents on the basis general combining ability, it was observed that most of the specific cross combination were the result of crosses between low $\times$ high or low $\times$ low or low $\times$ medium or high $\times$ high or high $\times$ medium general combiners in agreement with the finding.

In fact, cross L5 x L11 resulted from poor $\mathrm{x}$ poor inbred lines combination in each individual location showed that the crosses performed better than what would be expected from the GCA effects of their respective parents. Thus why, selection of crosses for grain yield improvement could depend on their specific combining ability. When high yielding specific combination are desired, especially in hybrid maize development, SCA effects could help in the selection of parental material for hybridization in the line and both additive and non-additive genetic action were important combining hybrids from the diallel crosses which was supported by $[43,48,18]$.

These results revealed that crosses with high specific combining ability in desired direction are contributed from parents with high and low general

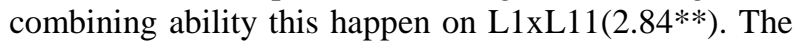
superiority of the crosses having low general combining ability parent may be due to high nicking ability of those parents with low general combining ability for example cross of L3xL5(1.39**) in line with the result finding of Prasanna [47]. Thus, in practice, some of the low combiners can also be recommended along with high combiners while planning breeding programs involving hybridization for production of hybrids, synthetics even composites.

The Specific combining ability effects are function of dominance and the product of the differences in allele frequencies of the parents, consequently they are related to the effects of dominance and epistasis [37]. Estimation of SCA effects for days to anthesis cross combination were L3 $\mathrm{x}$ L11 (7.16**), L7 x L12 (-4.86*), L9 x L10 (5.31**) and L8 x L11 (5.23**) express positive highly significant $(\mathrm{p}<0.01)$ SCA effects at Ambo; crosses of crosses of L1xL4 (4.31*), L3xL11 (4.65**); L3xL12 (5.77**) and L8xL11 $\left(6.35^{* *}\right)$ revealed highly significant $(\mathrm{p}<0.01)$ SCA effects at Holeta. Whereas cross combination that displayed negative significant SCA effects at Ambo were L7xL9 $\left(-4.43^{*}\right)$ and $\operatorname{LxL12}\left(-4.43^{*}\right)$ and at Holeta cross combination L1xL3 (-4.09*) and L6xL8 ($\left.4.45^{*}\right)$ as well.

For days to silking cross combination L1xL4 (5.48**), L5xL6 (5.35*), L8xL11 (8.72**) and L9xL10 $\left(6.55^{*}\right)$ showed highly and significant positive SCA effects at Ambo, while cross of L1xL4 (6.22**), L7xL12 $(4.79 *)$ and L8xL11 $\left(8.45^{* *}\right)$ recorded at Holeta. In the Contrary cross of L2xL6 (-4.05*), L5xL11 $\left(-6.28^{* *}\right)$, L6xL8 $\left(-4.32^{*}\right)$ and L6xL12 ($\left.4.05^{*}\right)$ displayed negative significant SCA effects at Ambo, however at Holeta cross combination of L1xL3 $\left(-7.41^{* *}\right), \operatorname{L} 4 x \operatorname{L} 6(-4.34 *)$ and L4xL79-4.57*) were provide negative SCA effects for the same traits.

The cross hybrids with negative SCA for days to anthesis and days to silking are desirable as they have earlier anthesis and silking days than what would be expected based on GCA of their parents. To the other side cross having positive SCA effects was late in tasseling and silking scored the longest day and became the highest yielder which could be due to the maximum photosynthetic product accumulation during the longer growing period. This finding is in agreement with Ahemd et al., [3]; Al-Falahy, [5]; Girma et al., 2015; Aslam et al., [9] and Matin et al., 2017. Crosses exhibited significant negative SCA effect considered as good combiner for the traits. This could be an indication that additive genetic effects were more important used inbreeding for early maturity.

Estimation of SCA effects for 1000-kernel weight attained by cross combination of L1 x L11, L2xL8, L4xL9, L5xL8 and L10xL11 positive and significant effects at Ambo ; L1 x L7, L7 x L8, L1 x L11, L4 x L9 and L5 x L8 showed positive and significant SCA effect for an increase thousand kernel weight at Holeta. Whereas L1xL7, L1xL11, L4xL9 and L5xL8 showed positive and significant SCA effects at Kulumsa.

For pooled data analysis of thousand kernel weight crosses L1xL6 (60.74**), L1x L7(93.74**), L1xL11(139.70**) , L2xL12(85.67**) , L3xL4 (89.96**) , L3xL5(66.97**) , L4xL9(110.35**) , L5xL8(108.14**) and $\operatorname{Lx} x \operatorname{L10}\left(48.77^{*}\right)$ attained positive and highly significant SCA effect followed by L10xL12 $\left(50.29^{*}\right)$ in the desirable direction. While to the undesirable direction cross of L1xL4 $\left(-114.06^{* *}\right)$, L1xL5 (-62.92**) , L3xL11(-98.9**), L3xL12(111.48**), L4xL10(-83.21**), 5xL7(-115.72**), L5xL9(-108.42**), L7xL12(-0.05**), L8xL11($31.12 * *)$ recorded highly significant SCA effect followed by L4xL6(-54.11*) and L8xL9 (-59.25*) which showed negative significant effect.

The general combining ability component of genetic variance $(35.64 * *)$ and SCA component $(139.07 * *)$ recorded high significant values indicated 
the role of both additive and non-additive gene action in the inheritance of 1000-kernel weight. This finding was in conformity with Ahmed, [47] and Dagne et al., [16].

This trait can be improved either by breeding methods by utilizing both the gene action such as selection, intercrossing among the selected best performed lines and reselection besides exploiting heterosis by production of hybrids, synthetics and composites. The cross having positive and significant SCA effects considered as good combiner for the traits and also had the highest combined analysis values. It could be concluded that the parental inbred line for that crosses could made themselves recombination. Similar results were obtained by $[26,1]$.

Table-17: Across location estimation of selected SCA effects for grain yield and yield related traits.

Table-17: Across location estimation of selected SCA effects for grain yield and yield
\begin{tabular}{|l|l|l|l|l|l|}
\hline Cross & ER(no) & HC(no) & KPR(no) & EL(cm) & ED(cm) \\
\hline L1xL2 & -2.95 & 0.13 & 2.56 & -1.09 & $0.37^{* *}$ \\
\hline L1xL3 & $11.05^{* *}$ & 0.6 & 1.52 & -0.41 & -0.26 \\
\hline L1xL4 & -3.22 & 0.5 & $-6.57^{* *}$ & $-2.36^{*}$ & 0.01 \\
\hline L1xL12 & -1.31 & -0.35 & -1.82 & -0.17 & $0.52^{* *}$ \\
\hline L2xL9 & $6.71^{*}$ & 0.12 & -0.47 & 0.41 & -0.05 \\
\hline L3xL9 & -0.96 & $-1.55^{* *}$ & -0.94 & 1.19 & -0.11 \\
\hline L3xL11 & $-3.92^{*}$ & -0.52 & 0.48 & 1.73 & -0.07 \\
\hline L3xL12 & -1.9 & $-1.51^{*}$ & -0.63 & $-2.32^{*}$ & -0.01 \\
\hline L4xL5 & $16.29^{* *}$ & 0.08 & -1.91 & -1 & 0.25 \\
\hline L4xL6 & $-7.58^{*}$ & -0.34 & 0.28 & -0.93 & 0.08 \\
\hline L4xL12 & 0.4 & $-1.41^{* *}$ & $3.85 * *$ & -1.6 & $-0.33^{*}$ \\
\hline L5xL12 & -2.94 & $1.23^{*}$ & 0.41 & 0.42 & -0.03 \\
\hline L6xL7 & 2.41 & $1.31^{*}$ & -0.07 & 1.13 & $0.40^{* *}$ \\
\hline L7xL12 & -5.22 & 0.15 & -0.5 & $-3.24 * *$ & -0.07 \\
\hline L8xL11 & -5.98 & $1.28^{*}$ & -2.71 & -1.54 & $0.39^{* *}$ \\
\hline L9xL10 & $-4.36^{*}$ & -0.24 & -1.35 & -1.2 & -0.02 \\
\hline L9xL11 & 0.01 & 0.26 & 0.3 & 0.25 & $-0.32^{*}$ \\
\hline L10xL12 & $7.06^{*}$ & 0.7 & -0.04 & $2.59^{*}$ & 0.14 \\
\hline SE(sij) & 4.72 & 1.15 & 2.87 & 2.08 & 0.34 \\
\hline SE(Si-sik) & 7.01 & 1.71 & 4.26 & 3.1 & 0.51 \\
\hline
\end{tabular}

** =highly significant $(\mathrm{p}<0.01),{ }^{*}=$ significant different $(\mathrm{p}<0.05), \mathrm{KPR}=$ number of kernels per row, EL =ear length, ED $=$ ear diameter, $\mathrm{HC}=$ husk cover, $\mathrm{ER}=$ ear rot, $\mathrm{SE}=$ standard error at $\mathrm{p}<0.05$ percent.

For bad husk cover and ear rot positive and significant SCA effects was observed at all location and across location except husk cover which attained nonsignificant effect at kulumsa. Those crosses which displayed negative significant SCA effects for the trait computed considered as desirable and good combiners for that traits. Crosses having good specific combination are preferred for good husk cover which manifested by negative and significant GCA effect to the desirable direction. Plants with good ear character that could be exploited in breeding programs for unopened husk cover and free ear rot were a feature of good husk cover ears as the current study revealed that in agreement with the authors Worku et al., [55] and Girma et al., [30].

Crosses showed highly significant positive GCA effect for husk cover and ear rot. This indicated the need for further effort to improve inbred line that have bad husk cover and ear rot gene and cross with other inbred lines that were good combiners for grain yield but contain undesirable genes for resistance to all bad cover and ear rot. In general, smaller value of (negative direction) specific combining ability was considered and also desirable for days to anthesis - to silking -to maturity, plant height, ear height, number of nodes per plant, while positive and significant specific combining ability was desirable for grain yield, ear length, ear diameter, number of kernels per row, number of row per ear and thousand kernel weight in loine with the report of Dufera, 2017.

\section{Summary AND CONCLUSIONS}

The development of maize variety for highland part of Ethiopia is a critical tasks for the breeder since one of the constraint now days in that area was luck of improved variety and they use maize as hunger breaking foods. This has been a major concern for my theses. Diallel crosses experiments with provide a powerful method of investigating polygenic systems.

This study was conducted at Ambo, Holeta and Kulumsa agricultural research center in the main cropping season of 2017. Twelve inbred lines were selected depend on their performance and diverse pedigree back grounds for the formation of $66 \mathrm{~F} 1$ crosses using half diallel mating design. Alpha lattice experimental design $(7 \times 10)$ was used with three 
replications at each location. Good level of variation was found for grain yield in all and across location. Among twelve inbred lines L2, L9 and L12 had good general combiners for grain yield and related traits since the lines showed positive general combining ability effects and L2 has also the best general combiner for traits such as; grain yield, days to silking, ear diameter, ear length and husk cover.

Parental line L9 has best general combiner for traits such as; grain yield, thousand kernel weight, days to silking- to-anthesis and ear rot. Whereas L12 has the best general combiner for traits such as; grain yield ear diameter, husk cover and ear rot. Therefore from this experiment I concluded that to increase the production and productivity of highland adapted maize, the concerned inbred lines was very important for developing improved varieties in maize breeding program. Mean square values of GCA variances for most of the traits at each location were higher than SCA variances; it means that there is dominance of additive gene action in loci. Genotypes revealed significant differences for all studied traits except, anthesis silking interval, root lodge, stem lodge, rust, leaf blight, days to maturity, and kernels per row indicated the existence of genetic variability.

Among the materials used for evaluation. The parents revealed highly significant differences for some studied traits such as grain yield, kernels per row, ear length, ear diameter, husk cover, ear rot indicating diversity in the parental lines with respect to the traits. All crosses in this study attained significant difference for some traits but not for grain yield which showed low varying performance of the lines in different combinations. Of all $66 \mathrm{~F} 1$ crosses evaluated, 14 F1 crosses out-yielded the check Argane, but chek-2 the newly released hybrid variety AMH852 (Kolba) exceed all cross in each and across location. The combined mean grain yield varied from $10.9 \mathrm{t}$ ha-1 (L5 x L12) to $4.4 \mathrm{t}$ ha-1 (L1xL4) for F1 cross combination. The cross (L5xL12) gave $26.7 \%$ yield advantage over the check Argane. L2, L9 and L12 have good combiner for grain yield and related traits since they showed positive GCA effect.

L1, L3 and L6 manifested negative GCA effects for kernels per row and ear diameter indicating that these lines contributed to reduce ear size or enhancing thinness in their era diameter.L11 manifested negative GCA effects over grain yield ,thousand kernels weight, kernel per rows, ear length and ear diameter indicated reduced yield by contributing poor allele frequency for cross combination.L1,L2,L3 and L12 attained negative GCA effects for husk cover and ear rot indicated minimizing bad husk cove and resistant to ear rot reaction. L2 showed negative GCA effects for days to anthesis and silking, revealed that the line contribute for earliness of the genotypes. The cross combination of L2xL12, L5xL12 and L9xL12 showed the better yield performance than all crosses evaluated but not than the check hybrid Kolba.

Concerning the crosses, since L2 x L11, L5xL12, and L9xL12 manifested positive and significant SCA effects for grain yield and related in the place where improved variety were constraint so use as a variety due to the high yielding potential of the cross combinations and also researchers will use for further study in breeding program to make three way crosses. The highest significant positive standard heterosis obtained by cross L2xL9 (72.12\%), L3xL12 (60.6\%), L5xL9 (72.72\%), L5xL12 (51.9\%) and L9xL12 $(43.94 \%)$.

In general, the study identified inbred lines and F1 (hybrid combinations) that had desirable expression of important traits which will be probably useful for the development of high yielding highland maize hybrids and synthetics varieties.

\section{REFERANCE}

1. Abdel-Moneam, M.A., Sultan, M.S., Sadek, S.E., \& Shalof M.S. (2015). Combining Abilities for Yield and Yield Components in Diallel Crosses of Six New Yellow Maize Inbred Lines. International Journal of Plant Breeding and Genetics, 9: 86-94

2. Ahmed, M.F. (2013). Diallel analysis and biochemical genetic markers for heterosis and combining ability under two sowing dates of maize inbred lines. Asian Journal of Crop Science, 5(1): 81-94.

3. Ahmed, A., Amiruzzaman, M., Begum, S., Billah, M. M., \& Rohman, M. M. (2014). Combining ability for yield and component characters in white grain quality protein maize. Bangladesh Journal of Plant Breeding and Genetics, 27(2), 9-15.

4. Al-Emnesh, A. (2012). Test cross performance and combining ability studies of elite maize (Zea mays L.) inbred lines in the central rift valley of Ethiopia (Doctoral dissertation, M. Sc. Thesis. School of Graduate studies, Jimma University, Ethiopia, PP: 243).

5. Al-Falahy, M. A. (2015). Estimation combining ability, heterosis and some genetic parameters across four environments using full diallel cross method. International Journal of Pure and Applied Sciences and Technology, 26(1), 34.

6. Seyoum, A., Wegary, D., \& Alamerew, S. (2016). Combining ability of elite highland maize (Zea mays L.) inbred lines at Jimma Dedo, South West Ethiopia. Advances in Crop Science and Technology, 1-9.

7. Aminu, D., Mohammed, S. G., \& Kabir, B. G. (2014). Estimates of combining ability and heterosis for yield and yield traits in maize population (Zea mays L.) under drought conditions in the Northern Guinea and Sudan savanna zones of Borno State, Nigeria. Int. J. Agr. Res. Innovat. Tech, 2(5), 824-830. 
8. Amiruzzaman, M., Islam, M. A., Hassan, L., \& Rohman, M. M. (2010). Combining ability and heterosis for yield and component characters in maize. Academic Journal of Plant Sciences, 3(2), 79-84.

9. Aslam, M., Sohail, Q., Maqbool, M. A., Ahmad, S., \& Shahzad, R. (2017). Combining ability analysis for yield traits in diallel crosses of maize. Journal of Animal and Plant Sciences, 27(1), 136-143.

10. Acquaah, G. (2009). Principles of plant genetics and breeding. John Wiley \& Sons.

11. Kumar, A., Dadheech, A., Kiran, N., Bisen, P., \& Kumar, S. (2017). Diallel Analysis of Combining Ability for Yield and Yield Contributing Traits over the Environments in Maize (Zea mays L.). Int. J. Curr. Microbiol. App. Sci, 6(10), 196-208.

12. Azad, M., Kalam, A., Hamid, M., Rafii, M. Y., \& Malek, M. A. (2014). Combining ability of pod yield and related traits of groundnut (Arachis hypogaea L.) under salinity stress. The Scientific World Journal, 2014.

13. Balaguer, C. M. (2014). Genetic Analyses of Growth, Carcass and Meat Quality Traits in Maternal Lines of Rabbits and Their Diallel Cross/Análisis Genético de Caracteres de Crecimiento, Matadero y Calidad de Carne en Lineas Maternales de Conejo y en su Cruzamiento Dialélico (Doctoral dissertation, Universitat Politècnica de València).

14. Bello, O. B., \& Olaoye, G. (2009). Combining ability for maize grain yield and other agronomic characters in a typical southern guinea savanna ecology of Nigeria. African Journal of Biotechnology, 8(11).

15. Berhanu, T. (2009). Heterosis and combining ability for yield related parameters and stover quality traits for food-feed in maize (Zea mays L.) Adapted to the mid-altitude agro-ecology of Ethiopia (Doctoral dissertation, MSc. Thesis, Haramaya University, Haramaya, Ethiopia 216p).

16. Chukwu, S. C., Okporie, E. O., Onyishi, G. C., Ekwu, L. G., Nwogbaga, A. C., \& Ede, N. V. (2016). Application of diallel analyses in crop improvement. Agric. Biol. JN Am, 7(2), 95-106.

17. Wegary, D., Vivek, B. S., Tadesse, B., Abdissa, K., Worku, M., \& Wolde, L. (2010). Combining Ability and Heterotic relationships between CIMMYT and Ethiopian Maize Inbred Lines and Ethiopian Maize Inbred Lines.

18. Wegary, D., Vivek, B. S., \& Labuschagne, M. T. (2014). Combining ability of certain agronomic traits in quality protein maize under stress and nonstress environments in Eastern and Southern Africa. Crop Science, 54(3), 1004-1014.

19. Makumbi, D., Assanga, S., Diallo, A., Magorokosho, C., Asea, G., Worku, M., \& Bänziger, M. (2018). Genetic Analysis of Tropical Midaltitude-Adapted Maize Populations under Stress and Nonstress Conditions. Crop Science, 58(4), 1492-1507.
20. Dar, Z. A., Lone, A. A., Alie, B. A., Ahangar, M. A., Ali, G., Abidi, I., ... \& Lone, R. A. (2018). Combining ability analysis for yield and yield contributing traits in Popcorn (Zea mays everta L.) under temperate conditions. J. Pharm. Phytochem, 7, 361-366.

21. Das, U. R., \& Islam, M. H. (1994). Combining ability and genetic studies for grain yield and its components in maize (Zea mays L.). Bangladesh J. Pl. Breed. Genet, 7(2), 41-47.

22. Abakemal, D., Zelleke, H., Kanuajia, K. R., \& Wegary, D. (2011). Combining ability in maize lines for agronomic traits and resistance to weevil (Sithophilus zeamais Motschulky). Ethiopian Journal of Crop Science, 2(1), 37-48.

23. Abakemal, D., Hussein, S., Derera, J., \& Laing, M. (2013). Farmers' perceptions of maize production systems and breeding priorities, and their implications for the adoption of new varieties in selected areas of the highland agro-ecology of Ethiopia. Journal of Agricultural Science,5(11), 159.

24. Demissew, A., Demoz, N., Worknesh, T., Emeshaw, D., Tefera, K., Legesse, W., Bayisa, A., Abiy, B Shimelis T, Leta, T., Melkamu, E., Habtamu, Z., Abusha, A., \& Tsegaw, S. (2018). Breeding Progress for Grain Yield in a Decade of Highland Maize Breeding in Ethiopia. Advance Agricultural Technique of Plant Sciences, 1(2): 180010

25. Falconer, D. S. (1994). Introduction to quantitative genetics .4th ed., John Whiley and sons, Inc., New York. 438

26. Fan, X.M., Y.M. Zhang, W.H. Yan, H.M. Chen., \& J. Tan. (2009). Classifying maize inbred lines into heterotic groups using a factorial mating design. Agron. J., 101: 106-112

27. FAO. (2013). Status of maize production and productivity in Ethiopia.

28. FAO. (2012). Analysis of Incentives and Disincentives for Maize in Ethiopia.

29. Akalu, G., Taffesse, S., Gunaratna, N. S., \& De Groote, H. (2010). The effectiveness of quality protein maize in improving the nutritional status of young children in the Ethiopian highlands. Food and Nutrition Bulletin, 31(3), 418-430.

30. Hosana, G. C., Alamerew, S., Tadesse, B., \& Menamo, T. (2015). Test cross performance and combining ability of maize (Zea mays L.) inbred lines at Bako, Western Ethiopia. Global $J$. INC.(USA), 15(4), 24.

31. Gomez, K. A., \& Gomez, A. A. (1984). Statistical procedures for agricultural research. John Wiley \& Sons.

32. Gosai, M. A., Kuchhadiya, G. V., Brahmbhatt, B. N., \& Bhalala, K. N. (2017). Study of Combining Ability in Diallel Crosses of Maize (Zea Mays L.) for Grain Yield and Quality Traits.

33. Griffing, B. R. U. C. E. (1956). Concept of general and specific combining ability in relation to diallel 
crossing systems. Australian journal of biological sciences, 9(4), 463-493.

34. Griffing, B. (1956). A generalised treatment of the use of diallel crosses in quantitative inheritance. Heredity, 10(1), 31-50.

35. Gurmu, G. N. Heterosis and combining abilities in QPM versions of early generation highland maize (Zea mays L.) inbred lines (No. Look under author name. CIMMYT.).

36. Hallauer. R. (2003). Internal Symposium on Plant Breeding, 22 August.2003. CIMMY, Mexico. Mexico, D. F. Heterosis and Combining Ability of CIMMYT's Tropical $\times$ Subtropical Quality Protein Maize Germplasm

37. Hallauer, A.R., \& Miranda, J.B. (1988). Quantitative genetics in maize breeding. $2^{\text {nd }}$ ed. Iowa State Univ. Press, Ames

38. Hill, J., Becker, H., \& Tigerstedt, P. (2012). Quantitative and Ecological Aspects of Plant Breeding. Springer Science and Business Media

39. Legesse, B. W., Pixley, K. V., \& Botha, A. M. (2009). Combining ability and heterotic grouping of highland transition maize inbred lines. Maydica.

40. Gichuru, L., Njoroge, K., Ininda, J., \& Lorroki, P. (2011). Combining ability of grain yield and agronomic traits in diverse maize lines with maize streak virus resistance for Eastern Africa region.

41. Machado, J. C., Souza, J. C. D., Ramalho, M. A. P., \& Lima, J. L. (2009). Stability of combining ability effects in maize hybrids. Scientia Agricola, 66(4), 494-498.

42. Azad, M. A. K., Biswas, B. K., Alam, N., \& Alam, S. S. (2014). Combining ability and heterosis for some quantitative traits in experimental maize hybrids. Plant Breeding and Seed Science, 70, 4154.

43. Matin, M. Q. I., Rasul, M. G., Islam, A. K. M. A., Mian, M. K., Ivy, N. A., \& Ahmed, J. U. (2016). Combining ability and heterosis in maize (Zea mays L.). American Journal of BioScience, 4(6), 84-90.

44. Worku, M., Bänziger, M., Friesen, D., Horst, W. J., \& Vivek, B. (2008). Relative importance of general combining ability and specific combining ability among tropical maize (Zea mays L.) inbreds under contrasting nitrogen environments. Maydica.

45. Sumalini, K., Pradeep, T., \& Sravani, D. (2016). Combining Ability Analysis over Environments in Diallel Crosses of Maize (Zea mays). Madras Agricultural Journal, 103.

46. Musila, R. N., Diallo, A. O., Makumbi, D., \& Njoroge, K. (2010). Combining ability of earlymaturing quality protein maize inbred lines adapted to Eastern Africa. Field crops research, 119(2-3), 231-237.
47. Ofori, A. P., Ofori, K., Obeng-Antwi, K., Tengan, K. M. L., \& Badu-Apraku, B. (2015). Combining ability and heterosis estimate of extra-early quality protein maize (QPM) single cross hybrids. Journal of plant breeding and crop science, 7(4), 87-93.

48. PRASANNA KUMAR, S. V. V. STUDIES ON COMBINING ABILITY IN MAIZE (Zea mays L.) USING DIALLEL ANALYSIS (Doctoral dissertation, ACHARYA NG RANGA AGRICULTURAL UNIVERSITY, GUNTUR).

49. Reddy, V. R., Jabeen, F., \& Sudarshan, M. R. (2015). Heterosis studies in diallel crosses of maize for yield and yield attributing traits in maize (Zea mays L.) over locations. International Journal of Agriculture, Environment and Biotechnology, 8(2), 271-283

50. Abrha, S. W., Zeleke, H. Z., \& Gissa, D. W. (2013). Line x tester analysis of maize inbred lines for grain yield and yield related traits. Asian journal of plant science and research, 3(5), 12-19.

51. Smith, B. D. (1989). Origins of agriculture in eastern North America. Science, 246(4937), 15661571.

52. Sprague, G. F., \& Tatum, L. A. (1942). General vs. specific combining ability in single crosses of corn 1. Agronomy Journal, 34(10), 923-932.

53. Tamirat, T., Alamerew, S., Wegary, D., \& Menamo, T. (2014). Test cross mean performance and combining ability study of elite lowland maize (Zea mays L.) inbred lines at Melkassa, Ethiopia. Advances in Crop Science and Technology.

54. Keno, T. (2013). Test cross evaluation of midaltitude maize (Zea mays L.) inbred lines for combining ability and identification of their heterotic pattern (Doctoral dissertation, MSc Thesis, Haramaya University, Ethiopia).

55. Twumasi-Afriyie, S., Zelleke, H., Yihun, K., Asefa, B., \& Tariku, S. (2002). Development and improvement of highland maize in Ethiopia. Enhancing the Contribution of Maize to Food Security in Ethiopia. EARO and CYMMIT, 31-38.

56. Vasal, S. K. (1998, February). Hybrid maize technology: Challenges and expanding possibilities for research in the next century. In Proc. 7th Asian Reg. Maize Workshop. Los Banos, Philippines, February (pp. 23-27).

57. Worku, M., Bänziger, M., Friesen, D., Horst, W. J., \& Vivek, B. (2008). Relative importance of general combining ability and specific combining ability among tropical maize (Zea mays L.) inbreds under contrasting nitrogen environments. Maydica. 